\title{
A MATERNIDADE SOB A ÓTICA DA TEORIA PULSIONAL ${ }^{1}$
}

Graciela Quintana Gómez

Doutora em Saúde Coletiva pelo Instituto de Medicina Social, Universidade do Estado de Rio de Janeiro (Uerj); com pós-doutorado na mesma instituição.
RESUMO: Pretende-se demonstrar que os diversos modos de entendimento da origem do psiquismo, presentes em determinados textos da metapsicologia freudiana, vinculam-se a diferentes formas de compreensão do tema da maternidade. Assim, em "Pulsões e seus destinos" (1915), a maternidade é associada a uma excitação externa que desorganiza o psiquismo do recém-nascido; por sua vez, em “Além do princípio do prazer" (1920) e "O problema econômico do masoquismo” (1924), há elementos de análise que possibilitam uma leitura alternativa sobre o tema, a partir das noções de masoquismo erógeno, pulsão de vida e de morte.

Palavras-chave: Maternidade, origem do psiquismo, passividade, intrincação pulsional.

ABSTRACT: The motherhood under the pulsional theory outlook. This work aims at demonstrating that the different understandings of the psyche's origins in certain texts of freudian metapsychology relate to different ways to comprehend maternity. Thus, in "The instincts' destiny" (1915), maternity is associated to an external arousal that disorganizes the newborn's psyche; on the other hand, an alternative reading of the theme based on notions such as erogenous masochism and life and death pulsions, is possible taking elements of analyses present in "Beyond pleasure principe” (1920) and "The economic problem of masochism" (1924).

Keywords: Maternity, origin of the psyche, passivity, fusion of instinct.

\footnotetext{
${ }^{1}$ Texto elaborado no âmbito da pesquisa no Instituto Fernandes Figueiras coordenada pelo professor Octavio Souza, com bolsa outorgada pela Faperj.
} 


\section{INTRODUÇÃO}

Este trabalho é uma reflexão sobre a maternidade, tendo como base o caminho aberto por Freud quando começa a entender a origem do psiquismo a partir da dimensão alteritária. A hipótese levantada é a de que a descoberta da pulsão de morte (FREUD, 1920/1973) e a introdução do conceito de masoquismo erógeno primário (FREUD, 1924/1973) para explicar a constituição do psiquismo possibilitam pensar a maternidade em termos de experiência de passividade ligada a Eros.

Esta leitura parte do suposto de que as diferentes teorias sobre constituição do psiquismo, presentes (embora não de um modo explícito) em determinados textos da metapsicologia freudiana, supõem duas formas de entender a maternidade, uma delas evocando a idéia de ameaça, e outra sendo vista como único recurso para que um movimento de vida possa ser instaurado no psiquismo do recém-nascido. Esta última significação, que neste estudo é trabalhada a partir de sua ligação com o masoquismo erógeno primário, incorpora a idéia de passividade como um caminho fecundo para pensar a maternidade, não no sentido de sua oposição à atividade, mas como movimento pulsional, psíquico e corporal, que evoca vida por meio de um processo de abertura, de receptividade.

A seguir, analisaremos estas duas representações, separadamente, e na ordem indicada, para depois, num terceiro momento, nos centralizar nas conclusões, tentando inferir os efeitos e conseqüências de um estudo como este, que, partindo de um questionamento da concepção dominante sobre maternidade na teoria psicanalítica freudiana, explora outros modos de aproximação ao tema.

\section{A MATERNIDADE, UMA EXCITAÇÃO QUE AMEAÇA}

A associação entre maternidade e ameaça está presente (de modo mais ou menos explícito) em diversos textos freudianos: na carta-poema enviada a Fliess (FREUD, 1899) pelo nascimento de seu filho, em que a idéia de ameaça é associada à maternidade, vista como uma "potência do sexo feminino" que pode levar a uma “desagregação" se o pai não intervém introduzindo a dimensão da lei (SCHNEIDER, 2000, p.56); nos Três ensaios para uma teoria sexual (1905/1973) e em Leonardo da Vinci e uma lembrança de sua infância (1910/1973), em que fala de uma ternura materna excessiva que pode ser fatal para o filho (SCHNEIDER, 1980, p.216-7); e na teoria catártica depois abandonada, quando o "mal psíquico” ou o "corpo estrangeiro", que deve ser expulso, é relacionado ao corpo feminino (SCHNEIDER, 1992, p.9).

Neste trabalho, no entanto, vamos nos centralizar num texto de Freud que trata da questão não tão direta nem explicitamente ligada à sexualidade feminina e maternidade, mas referida à origem e constituição do psiquismo — o artigo da metapsicologia Pulsões e seus destinos (1915/1973). Nele, para chegar onde queremos, 
ou seja, na maternidade, temos que substituir as palavras "excitação externa" (ou “meio externo”, também utilizada) pela palavra "mãe”. É necessário esclarecimento isto para mostrar o que está em jogo em Pulsões e seus destinos (FREUD, 1915/1973) em relação a este tema, o qual, sem dúvida, a compreensão se vê dificultada porque se fala em excitação, mundo externo, meio externo, sistema nervoso, aparato psíquico, pulsão, arco reflexo, princípio de prazer, sem fazer nenhuma menção à relação específica do filho com a mãe. O que propomos, então, é substituir termos, imaginar outros cenários quando lemos o texto, de modo a perceber como Freud imagina esse momento originário no qual as personagens principais são o filho recém-nascido e a mãe, e que visão de maternidade sugere na concepção de psiquismo que constrói ali. E digo 'sugere', e não 'constrói', porque, de fato, Freud não fala de modo específico de maternidade neste artigo (a mesma observação vale para os outros dois artigos que serão trabalhados no próximo ponto). Este é nosso esforço, nosso trabalho, apoiado no pensamento de determinados autores, como veremos a seguir.

A partir de leituras singulares, vários autores trabalham, hoje, as diversas formas de tratar a questão da origem do psiquismo presentes em Freud (SCHNEIDER, 1980; BIRMAN, 1999; SISSA, 1999; DAVID-MÉNARD, 2000). Na análise de Pulsões e seus destinos (FREUD, 1915/1973), no qual Freud elabora uma destas formas, nossa referência teórica principal é Monique Schneider, por sua maneira inovadora de conduzir seu estudo no livro Freud et le plaisir (1980), ao articular de modo explícito a questão da origem do psiquismo com a questão do masculino, fundamentada na ênfase outorgada neste artigo freudiano à noção de atividade, entendida no sentido de domínio, de controle de qualquer excitação que venha do exterior. É esta interpretação que me leva a privilegiar a autora. A associação que ela sustenta entre as idéias de ativo/masculino/domínio, expressa em sua leitura crítica de Pulsões e seus destinos (FREUD, 1915/1973), prepara o terreno, pode-se dizer, para o próximo tema em que a idéia de passividade (como foi anunciado na introdução e como veremos mais adiante) adquire uma significação que reflete outros modos de entender a maternidade e a origem do psiquismo. Mas abordemos antes a representação de maternidade que se vislumbra em Pulsões e seus destinos (FREUD, 1915/1973).

O paralelo estabelecido por Freud entre o funcionamento do sistema nervoso em suas origens (descrito a partir de argumentos biológicos) e o funcionamento do aparato psíquico submetido ao princípio de prazer, sustentando que em ambos os casos é privilegiada a mesma idéia — de atividade, ação, entendidas num sentido semelhante, enquanto domínio, diminuição ou supressão das excitações - é a base na qual se apóia a interpretação de Schneider. Existe um postulado de natureza biológica cujo conteúdo é o seguinte, escreve Freud: 
“O sistema nervoso é um aparato cuja função principal é afastar as excitações que chegam a ele, reduzi-las ao máximo e, se fosse possível, manter-se livre de toda excitação (...). Quando depois constatamos que a atividade dos aparatos psíquicos também está submetida ao princípio de prazer (ou seja, regulada automaticamente pelas sensações da série de prazer/desprazer), já nos resulta difícil rechaçar um novo pressuposto: que essas sensações de prazer/desprazer reproduzem o modo como se desenvolve o domínio das excitações, no sentido em que o desprazer se relaciona com um aumento de excitação e o prazer com uma diminuição da mesma." (FREUD, 1915/1973, p.2.041)2

A partir destas formulações freudianas, que revelam o privilégio outorgado às noções de defesa e domínio em relação às excitações, a autora postula que esse pensamento implica, por um lado, identificar maternidade (excitação externa) com um elemento desorganizador para o psiquismo do recém-nascido, e, por outro lado, demonstrar que a origem da vida não depende de uma causa exógena (excitação externa), ou seja, que o bebê é capaz de gerar-se a si mesmo em sua relação com o prazer. Ao analisá-los, veremos que, em realidade, estes dois postulados estão intimamente ligados, um decorrendo do outro. Vejamos, a seguir, o primeiro deles, a identificação da mãe como um elemento desorganizador para o psiquismo.

\section{A MATERNIDADE COMO ELEMENTO DESORGANIZADOR DO PSIQUISMO DO RECÉM-NASCIDO}

A idéia de um psiquismo ativo, guerreiro, segundo Schneider (1980), atravessa o texto freudiano de ponta a ponta, manifestando-se desde o primeiro momento através do esquema do arco reflexo (ao qual Freud recorre apelando à fisiologia) que, sem dúvida, resolve o problema colocado pelas excitações externas:

“A fisiologia nos deu o conceito de excitação e o esquema do arco reflexo segundo o qual uma excitação que vem do exterior para o sujeito vivo é descarregada novamente para o exterior sob a forma de ação. Esta ação é apropriada na medida em que subtrai a substância excitada da ação da excitação e a afasta de sua influência." (FREUD, 1915/1973, p.2.040)

A imagem de um bebê fugindo da mãe (excitação que vem do exterior) se vislumbra neste enunciado, sendo reforçada algumas linhas depois, quando Freud explica o modo como se constitui o psiquismo do recém-nascido: imaginemos um bebê desamparado, perdido no mundo, sem nenhuma defesa contra o meio

\footnotetext{
${ }^{2}$ As traduções das citações dos livros em francês e castelhano são livres.
} 
externo, mas que, graças à eficácia de sua ação muscular (fuga), rapidamente consegue uma primeira orientação que lhe permite distinguir quais excitações vêm do mundo externo, escreve Freud. Detenhamo-nos aqui, neste ponto. Mais adiante, continuaremos esta descrição. O importante neste momento é nos centrarmos no modo como é visualizado o meio externo (ou seja, a mãe). A forma como Freud fala de desamparo neste parágrafo evoca uma ausência materna: a mãe não existe. Existe apenas um bebê dotado de um mecanismo automático, mecânico (o esquema do arco reflexo) ou de um princípio científico, absoluto (o princípio de prazer), que se apresenta como regulador do psiquismo, associando prazer à diminuição de excitação e desprazer ao aumento da mesma. Nesta descrição da origem do psiquismo, a ênfase num bebê "musculoso", "eficaz”, como diz Schneider (1980, p.112), que rapidamente supera o estado de desamparo inicial tornando-se dono de si; na idéia de ação, que neste caso se expressa através da reação de fuga; e, por fim, na imagem de um exterior que suscita apenas reações defensivas e discriminatórias, explica a identificação da maternidade com uma excitação externa e, portanto, com desprazer (segundo a lógica do princípio de prazer), como se o mundo externo não pudesse expressar-se de outro modo. Em Pulsões e seus destinos (FREUD, 1915/1973), à diferença dos outros dois textos da metapsicologia freudiana que analisaremos mais adiante - Além do princípio de prazer (1920/1973) e O problema econômico do masoquismo (1924/1973) —, o meio externo (mãe) não é solicitado, não pode ajudar. Aqui, é impossível pensar em termos de um meio necessário, que deve intervir para auxiliar o recém-nascido na localização e apaziguamento das excitações, propiciando, desse modo, um movimento de vida no psiquismo do recém-nascido. Apresenta-se, ao contrário, a imagem de um bebê vitorioso, que logo domina o desamparo inicial e aprende a defender-se, sozinho, supostamente sem nenhum auxílio externo (graças apenas aos movimentos de seu corpo) de tudo aquilo que, desde fora, supostamente o agride. Schneider vê o próprio Freud, teórico, construindo um saber metapsicológico sobre as origens do psiquismo contra a figura materna, identificada com uma figura ameaçadora, “o monstro que é necessário reduzir para anular magicamente uma origem...” (SCHNEIDER, 1980, p.115).

Retomemos Freud, em sua descrição sobre o funcionamento do sistema nervoso no primeiro tempo após o nascimento, mas agora a partir de outro princípio mencionado em Pulsões e seus destinos (FREUD, 1915/1973), referido às excitações pulsionais internas, ou seja, às pulsões propriamente ditas. Que acontece neste caso, quando a excitação desprazerosa vem de dentro e não de fora? O esquema do arco reflexo, como acabamos de ver, resolve o problema causado pelas excitações externas. Mas, e as excitações internas, como acalmá-las, como apaziguá-las, se, neste caso, a atividade da fuga é impossível? Aqui, Freud se vê obrigado a apelar ao outro; o outro (meio externo, mãe) é necessário; sem ele a vida 
se torna impossível porque o recém-nascido não pode fugir das excitações que, de dentro dele, o perturbam, diz Freud. As excitações pulsionais estão ligadas a um estado de necessidade, como podem ser a fome ou o frio, por exemplo; elas são constantes no sentido em que o psiquismo não pode fugir delas. Neste caso, apresenta-se um problema que não existia no outro: como não se pode fugir da excitação pulsional que vem do interior do próprio corpo, o sistema nervoso tem que deixar de lado sua tendência natural a eliminar toda excitação (tendência biológica, reproduzida no aparato psíquico através do funcionamento do próprio princípio de prazer), e "começar a realizar complicadas atividades relacionadas entre si, que modificam o mundo externo até que este acabe oferecendo a satisfação pedida pela excitação interna” (p.2041). Aqui, Freud está se referindo ao choro ou ao grito do bebê que chama a mãe para que ela realize a “ação específica”. Mais que como meio de comunicação com o outro, revelador da vulnerabilidade e desamparo do recém-nascido - como no Projeto (FREUD, 1895/1973) — , estas manifestações do bebê figuram em Pulsões e seus destinos como prova de que "o verdadeiro motor do progresso" (1915/1973, p.2041), o motor do desenvolvimento do sistema nervoso, encontra-se nas próprias pulsões, não no mundo externo.

O bebê imaginado por Freud em Pulsões e seus destinos se vê, então, obrigado a pedir ajuda externa para resolver o desprazer causado pelas excitações internas, das quais não pode fugir. O exterior, antes visto como ameaçador é, assim, transformado em satisfação, mas em uma satisfação pontual, que supostamente acalmaria um estado de necessidade também pontual, enfatiza Schneider: nada de toques, carícias, sons. Assim visualizado, o corpo materno aparece, sim, mas apenas como recurso para acalmar a fome ou o frio; como remédio, tranqüilizante. Toda excitação (externa) imprevisível, ocasionada por iniciativas que não entrem na satisfação restrita da necessidade, neste texto, são impossíveis. Em um contexto como este não há espaço — teórico — para que o prazer possa entrar como movimento trazido pela excitação externa, imprimindo algo novo. O único prazer viável consiste em suprimir o estado de desprazer originado nas excitações internas, das quais não se pode fugir. O bebê tem à disposição um mecanismo regulado pelo princípio de prazer que o levará, automaticamente, a rejeitar qualquer excitação (externa) que não se limite a satisfazer à necessidade, eliminando ou diminuindo a excitação interna. Se esse dispositivo não funciona bem e não consegue deter a excitação (externa), a excitação (externa) que se infiltra nunca poderá ser sentida como prazerosa porque a idéia de prazer, anexada ao princípio do mesmo nome (o princípio de prazer), equivale a uma diminuição da excitação.

Assim figura a mãe em Pulsões e seus destinos. Esta construção sugere, portanto, que, neste artigo, Freud quis, sobretudo, mostrar a autonomia da pulsão, sua ativi- 
dade no sentido do domínio do outro. Em nosso entender, não é a idéia de atividade que deve ser questionada, e sim a de dar a esta uma significação de domínio - e nada além disso - por meio da imagem de um aparato psíquico regido pelo princípio de prazer, que busca vencer a excitação externa; em outras palavras, por meio de um bebê que luta contra a mãe. Uma idéia que deve ser revisada, ainda mais porque neste trabalho privilegiamos um momento muito inicial, de muita vulnerabilidade tanto para o filho como para a própria mãe, em que o que está em jogo é sua possibilidade de favorecer movimentos de vida no filho no tempo imediatamente posterior ao nascimento, quando ela mesma acaba de vivenciar a experiência do parto. Como falar nesses termos — de um exterior desorganizador — num contexto como este, quando mãe e filho estão tão juntos (um dependendo do outro, poderíamos dizer) para que o movimento de vida possa instaurar-se e consolidar-se? É nessa direção que desejamos transitar, privilegiando a idéia de encontro, e não a de separação ou de defesa em relação à maternidade. Como diz Schneider, no artigo intitulado "La proximité chez Levinas et le Nebenmensch freudien” (1991): a vulnerabilidade e o desamparo presentes não apenas no recém-nascido, mas também na própria mãe, devem ser vistos como fonte de comunicação, encontro, humanização, e não como obstáculo.

\section{UMA VISÃO SOLIPSISTA DO PSIQUISMO}

Vejamos agora o segundo postulado. A concepção de prazer defendida por Freud em 1915, associada a uma diminuição da excitação, além de supor a identificação da excitação externa com elemento perturbador do psiquismo em formação, por outro lado, como foi dito, supõe uma visão solipsista do psiquismo, sustentada na crença de que o motor da vida está na própria pulsão, ou seja, no próprio bebê; como se a vida viesse de dentro, não de fora, não do outro. Por isso se compreende que a excitação externa seja considerada, além de desorganizadora, elemento do qual se pode prescindir. Em Pulsões, Freud pensa que a pulsão com a qual o bebê nasce, e a atividade que lhe é inerente, explicam, por si sós, que a vida vem de dentro, de um mecanismo endógeno regulado pelo princípio de prazer, que funciona de modo automático no sentido da diminuição ou eliminação das excitações. A imagem é de um bebê desamparado que rapidamente começa a orientar-se no mundo - a tornar-se dono de si, segundo expressão de Schneider - ao conseguir distinguir o externo e o interno, graças ao mecanismo de fuga. O externo é aquilo que ameaça, no sentido em que causa desprazer, do qual ele pode fugir graças ao mecanismo da fuga. O interno é aquilo do qual não pode fugir, associado, como dissemos, a um estado de necessidade. Neste último caso, a visão solipsista é relativizada, porque, como acabamos de ver, o outro é requerido, sim, precisa-se de sua intervenção, mas apenas para salvar 
o recém-nascido da fome, do frio ou de qualquer outro estado de necessidade semelhante, ou seja, apenas como remédio, como instrumento para eliminar o estado de necessidade, mas não como alguém capaz de imprimir traços novos no psiquismo. Como falar em termos de alteridade neste caso, quando o outro é solicitado de modo tão controlado, tão pontual? Como falar em termos de alteridade, de instauração de um processo de humanização entre dois seres tão unidos, se permanecermos na lógica do tudo-ou-nada, imposta pelo funcionamento do princípio do prazer — tudo-ou-nada no sentido de associar prazer à diminuição/eliminação da excitação, desprazer a aumento de prazer, como se nada mais existisse?

É importante, então, ressaltar a correspondência entre três idéias — prazer, excitação, visão solipsista/vitalista do psiquismo - para postular, como acabamos de ver, que o modo como o prazer e a excitação são entendidos em Pulsões supõe uma visão solipsista do psiquismo, e, por outro lado, que esta correspondência implica uma visão da maternidade, que privilegia as idéias de afastamento, separação. Uma visão que deve ser revista, em relação à qual o próprio Freud indica um caminho diferente de abordagem, quando mais tarde descobre que o princípio que rege a vida psíquica não é o princípio de prazer, mas o princípio de inércia (pulsão de morte), como veremos a seguir, no próximo ponto. A força que adquire a dimensão alteritária nesse novo contexto teórico inaugura um modo de entender a origem do psiquismo que permite uma aproximação diferente ao tema da maternidade. Antes de abordá-lo, porém, um esclarecimento: não se trata de substituir uma visão da maternidade por outra, mas de incluir sentidos antes desconsiderados, relacionados às idéias de prazer e de excitação, os quais tornam mais fecunda esta reflexão, ao possibilitar a integração da idéia de masoquismo erógeno, entendida como experiência de passividade ligada à vida e a Eros. Esta problemática é a que trabalhamos a seguir, tendo como base teórica os outros dois textos da metapsicologia freudiana antes mencionados: Além do princípio de prazer e O problema econômico do masoquismo.

\section{OUTRAS FORMAS DE ENTENDER A MATERNIDADE}

Em Além do princípio de prazer e O Problema econômico do masoquismo, Freud começa a lançar conceitos novos. Pulsão de morte, pulsão de vida, um modo diferente de entender a questão do prazer, masoquismo erógeno primário. Todas estas noções surgem juntas, umas como que chamadas pelas outras, poderíamos dizer, para dar conta da importância que vai adquirindo a questão do outro em seu pensamento. Que significa a idéia de alteridade neste contexto? Significa que sem o outro não vivemos, que sem o outro é impossível qualquer movimento instaurador de vida. É sobre isto, em definitivo, que Freud fala em Além. 
Neste sentido, pode-se pensar que quando Freud introduz a idéia da pulsão de morte, em 1920, está falando também de vida porque está dizendo que para que a instauração de um movimento de vida no recém-nascido — ou seja, para que possa ser impedida a tendência primeira do organismo no sentido do retorno ao inanimado - seja possível, é indispensável a presença da mãe (ou substituto). A mãe, então, é o outro; ela representa a dimensão alteritária, conseqüência da descoberta da pulsão de morte. Dito de outro modo, a partir da descoberta da pulsão de morte, a ênfase no princípio do prazer se desloca para a dimensão alteritária: a mãe possibilita a vida ao obstaculizar o primeiro movimento do bebê no sentido da descarga absoluta, da volta ao inorgânico.

Em 1920, Freud descobre a partir da experiência clínica — da compulsão á repetição na transferência — , que a característica de toda pulsão não é a tendência à evolução e ao progresso (como afirmava em 1915) senão, ao contrário: a tendência a reconstruir um estado anterior que foi abandonado devido à influência de forças exteriores. Volta ao inorgânico, volta ao inanimado, assim se expressa Freud ao referir-se à pulsão de morte. Em outras palavras, o que ele quer dizer é que a possibilidade de instaurar o movimento de vida no recém-nascido está no mundo externo (na mãe) e não na própria pulsão (bebê); ou que a excitação, que em 1915 era vista como invasora, levanta-se agora como único recurso para a vida. Estas são duas maneiras de expressar a mesma idéia. A dimensão alteritária, esboçada em Três ensaios para uma teoria sexual através do auto-erotismo - a criança "se torna auto-erótica" no momento que perde o primeiro objeto da pulsão sexual (FREUD, 1915/1973, p.1225) - ${ }^{3}$ torna-se evidente em Além do princípio de prazer, quando o outro é incorporado desde o primeiro momento, quando não se quer afastá-lo, como em Pulsões e seus destinos.

Em 1920, ao contrário, busca-se a união; esse é o elemento novo. No mesmo lugar em que antes se via o perigo (no exterior, na excitação externa), agora se vê a única salvação; e inversamente, onde antes se refletia a vida, ou ao menos sua conservação (na própria pulsão do recém-nascido) teme-se agora a morte. Em Além do princípio de prazer, a excitação externa é vida. Não é necessário montar todo um aparato defensivo contra a excitação porque é graças a ela que se pode bloquear a tendência interna do indivíduo no sentido do retorno ao inanimado. A união com outras substâncias vivas, análogas, mas diferentes, produz

\footnotetext{
${ }^{3}$ Dizemos que a dimensão alteritária está presente em Três ensaios para uma teoria sexual (embora não de modo sistematizado como em 1920 e 1924) porque neste texto freudiano a amamentação não aparece como satisfação de uma necessidade pontual, mecânica (como em Pulsões e seus destinos, em que, como dissemos, o outro era apenas o meio utilizado para acalmar a fome ou o frio), mas como atividade que vem acompanhada de um prazer entendido não apenas como apaziguamento de uma excitação, mas também como movimento de abertura, estímulo que revela ao bebê uma nova sensação (FREUD, 1905/1973, p.1.200).
} 
um aumento de tensões cujo resultado é a vida. Rejuvenescimento, renovação, reforço, impulso, todos esses termos que Freud utiliza mostram a presença, a evidência da pulsão de vida, revelando que estamos diante de uma modificação da teoria da excitação.

Até agora, fomos integrando na segunda parte deste trabalho diferentes idéias: pulsão de morte, dimensão alteritária, excitação, pulsão de vida. E a questão do prazer; qual é seu lugar e sua importância neste novo entendimento das origens do psiquismo? Vejamos.

A transformação teórica inaugurada em 1920 a partir da descoberta da pulsão de morte será reforçada em 1924, em O Problema econômico do masoquismo, quando Freud reconhece de modo mais explícito e sistematizado que, de fato, o que desperta para a vida é a excitação de origem externa, pois não existe nenhum princípio endógeno automático (como o "princípio de constância” ou o "princípio do prazer”) que assegure a própria conservação.

Esta nova concepção alteritária e não mais solipsista do psiquismo nos introduz, de cheio, na questão do prazer. Em que sentido? Se a excitação é restaurada, isto é, se a participação do outro passa a ser vista como indispensável para instaurar a ordem da vida, a definição de prazer que vigorou durante muitos anos, associada a uma diminuição ou eliminação da excitação, deve ser modificada: o prazer não pode mais ser associado à extinção da excitação porque isso significaria deixar o outro de lado. Schneider destaca que mais que de uma transformação radical da definição de prazer, trata-se de introduzir um movimento em seu seio, indicando que é por meio do masoquismo erógeno, finalmente reconhecido em sua dimensão originária, que o prazer será por fim desvinculado de seu primitivo objetivo de extinção de tensões. Nas palavras da autora: é no artigo de 1924, então, no qual "Freud se volta sobre as definiçõos inaugurais do prazer, para colocar em questão a equação fundamental, que identifica prazer e diminuição de tensão" (SCHNEIDER, 1980, p.236).

Que significa masoquismo erógeno originário; qual é sua ligação com os conceitos anteriores; em que medida ele contribui para avançar na compreensão da origem do psiquismo e da maternidade? O princípio de prazer, considerado antes a primeira lei do funcionamento psíquico, passa a ser visto como secundário em relação à pulsão de morte, secundário no sentido em que introduz uma modificação na pulsão de morte possibilitada graças à intervenção da pulsão de vida e, também, como veremos a seguir, do próprio masoquismo erógeno primário. Para Freud, a força da qual provêm a modificação da pulsão de morte “é apenas a pulsão de vida, a libido, a qual conquistou desse modo um lugar ao lado da pulsão de morte na regulação dos processos de vida” (1924, p.2.753). Essa modificação só pode acontecer, é claro, supondo o que chamamos intrincação pulsional, a ligação da pulsão de morte pela libido. Falar nesses termos — pulsão 
de morte, pulsão de vida, intrincação pulsional, princípio de prazer não mais identificado com extinção das excitações — é, em definitivo, falar em termos de masoquismo erógeno primário. É isso o que Freud nos diz quando se refere a esse masoquismo como o "testemunho" ou o "vestígio" (p.2.755) dessa fase de formação em que se ligam pulsão de morte e pulsão de vida.

Então, se o masoquismo erógeno primário é definido pela intrincação pulsional e, simetricamente, a primeira e mais original das intrincações pulsionais realiza-se no masoquismo erógeno primário, essa dupla relação faz com que a intrincação pulsional seja, em essência, masoquista. Masoquista apenas no sentido em que ela erotiza a pulsão de morte por meio de um movimento pulsional de passividade, entendido no sentido de receptividade, abertura. Esta idéia é importante porque mostra as diferentes formas de entender o masoquismo presentes em Freud, ou seja, demonstra que há, também, um masoquismo ligado à vida. Ela será mais bem compreendida a partir do que Freud diz sobre o princípio de prazer e sua articulação com o masoquismo erógeno originário. Em realidade, resulta difícil falar em separado de todos esses conceitos que estão sendo introduzidos porque eles estão intimamente ligados entre si, todos referidos ao momento inicial da vida. Um leva ao outro; às vezes, um é ao mesmo tempo o outro, como no caso da intrincação pulsional e do masoquismo erógeno primário. Vejamos, então, a relação entre masoquismo erógeno primário e princípio de prazer.

$\mathrm{Na}$ anterior concepção de prazer, o princípio de prazer podia acabar se identificando com pulsão de morte (no sentido da eliminação de toda excitação, ou seja, da busca de um prazer absoluto, entendido como ausência total de excitação), mas, graças à intervenção do masoquismo erógeno, a tendência ao prazer absoluto é evitada, e o princípio de prazer, modificado, passa a representar a possibilidade de uma vivência relativizada de prazer. Que significa isso? Significa que estamos diante de uma idéia mais complexa de prazer, que integra também o desprazer, e que compreende tanto a excitação como a eliminação da excitação, ou seja, a descarga.

Como observa Rosenberg (2003), autor que realiza um estudo aprofundado sobre o conceito de masoquismo erógeno primário e que, do mesmo modo que Schneider, também permite avançar na reflexão sobre a maternidade: antes havia um corte, uma separação entre excitação e descarga; agora não, o prazer masoquista erógeno primário aparece como modelo de prazer porque liga excitação e descarga em um processo vital que possui sua própria temporalidade. Esse ritmo interno é pautado pela capacidade de suportar o desprazer, ou pela capacidade de suportar o desamparo, que leva a questionar e abandonar a velha associação prazer/descarga, desprazer/excitação. Freud define o masoquismo erógeno primário como aquela parte da pulsão de morte que não 
se descarrega para o exterior senão que, ao contrário, permanece no interior do organismo, onde fica ligada libidinalmente com a ajuda da co-excitação sexual. Dito de outro modo: no momento originário, imediatamente posterior ao nascimento, quando a pulsão de vida encontra a pulsão de morte (reinando, querendo levar tudo ao inorgânico), erotiza-a, graças ao desvio de parte dela para dentro do organismo. Esse é o “momento", o “lugar”, do masoquismo erógeno, experiência que possibilita a própria instauração do ciclo vital, primeiro esboço da vida psíquica, mas que também se dá em nível orgânico. O masoquismo erógeno primário ou a intrincação pulsional primária, é “o traço de união entre o orgânico e o psíquico”, como salienta o autor (p.100), por isso falamos em termos de "momento" e de "lugar", para ressaltar a íntima vinculação dessa experiência originária com o corpo, entendido como espaço, como lugar onde ela acontece.

Qual é o papel atribuído ao objeto, ou seja, à mãe, nesta visão da origem do psiquismo? "É a mãe que se encarrega da ligação da pulsão de morte pela libido, considerando-se que a criança não pode fazê-lo por si mesma” (p.102); dela depende a qualidade da intrincação primária, ou seja, “a existência de um núcleo masoquista primário sólido, que assegure uma continuidade interna suficiente (p.103). Nesse sentido, pode-se dizer que a pulsão de vida é a própria mãe, pois é ela quem impede (com seus cuidados e sua presença) os movimentos pulsionais do bebê em direção à descarga absoluta. Bloquear a descarga total significa fazer com que a pulsão volte para o recém-nascido, imprimindo traços de prazer (excitação que estimula) e fazendo, também, com que o desprazer possa ser vivenciado de modo erotizado. Rosenberg, preocupado com a clínica, desenvolve e explora a idéia de masoquismo erógeno primário como núcleo que se forma no próprio sujeito (traço de união entre o orgânico e o psíquico), e que funciona como guardião de nossa vida (na medida que impede o movimento de descarga absoluta, de modo erotizado, ligado à vida). Assim, ele observa que o masoquismo erógeno primário se constitui por meio do outro (a intervenção da mãe bloqueando a satisfação da pulsão de morte), mas depois começa a funcionar no interior do próprio sujeito, como guardião que ajuda a suportar o desamparo, assegurando desse modo uma continuidade interna. Neste trabalho, no entanto, o objetivo principal foi pensar a questão do masoquismo erógeno primário a partir de sua vinculação com a problemática ligada à origem do psiquismo, de modo a buscar uma aproximação ao tema da maternidade a partir da idéia de passividade, integrando corpo e psiquismo, prazer e desprazer numa mesma experiência pulsional ligada à vida. 


\section{CONCLUSÕES}

Foi percorrido um longo caminho para chegar onde queríamos, ao conceito de masoquismo erógeno originário e seu vínculo com a maternidade. Um caminho que começou distinguindo, nos textos da metapsicologia freudiana que tratam da origem do psiquismo, a presença de diferentes modos de entender a maternidade que, sem estar explicitados, eram vislumbrados, ou sugeridos. Para aprofundar e dar consistência a esta idéia foi necessário um trabalho de exploração desses textos, o que nos levou a imaginar outro cenário, no qual a mãe e o bebê eram os personagens principais, de modo a poder avançar em nossa hipótese de trabalho, que, sem dúvida, encontra-se dificultada pela linguagem utilizada, uma linguagem mecanicista, que pode levar a pensar que Freud não trata a questão da relação de objeto nos textos da metapsicologia. Um dos objetivos principais neste trabalho foi demonstrar que sim, que esta questão está presente nos escritos aqui analisados; que há neles uma reflexão sobre o vínculo primordial mãe/bebê, da qual, por outro lado, é possível inferir duas formas diferentes de entender a maternidade — ou como elemento externo do qual é preciso defender-se, sobretudo e antes de mais nada defender-se (Pulsões e seus destinos); ou como único recurso para que o ciclo da vida possa ser instaurado no psiquismo do recém-nascido (Além do princípio de prazer e O problema econômico do masoquismo).

Ao incorporar elementos antes não considerados — uma nova forma de entender o prazer; a idéia de masoquismo erógeno originário evocando a união corpo/psiquismo através de uma experiência de passividade ligada à vida — - esta última significação possibilita uma compreensão diferente da maternidade, na qual a idéia de vulnerabilidade adquire importância, e nos interpela, no sentido de alertar e de insistir na necessidade do cuidado materno: para poder propiciar no recém-nascido a formação de um espaço em que a vida possa começar a circular e a despregar-se, a mãe precisa ela mesma ter a possibilidade de vivenciar sua própria experiência de maternidade (gravidez, parto, pós-parto) como experiência de passividade — passividade entendida não como oposta à atividade, como já foi dito, mas como receptividade, entrega, abertura.

Recebido em 4/11/2006. Aprovado em 11/12/2006. 


\section{REFERÊNCIASS}

BIRMAN, J. (1999) "O corpo, o afeto e a intensidade em psicanálise”, in A psicanálise e as novas formas de subjetivação: Mal-estar na atualidade. Rio de Janeiro: Civilização Brasileira.

CHALIER, C. (1985) “Éthique et feminine”, in Cahiers du Grif: L’Indépendance amoureuse. Bruxelles. Michel.

(1998) Pour une morale au delá du savoir. Kant et Levinas. Paris: Albin

KRISTEVA, J. \& CLEMENT, C. (1998) Le Féminin et le sacré. Paris: Stock.

DAVID-MÉNARD, M. (2000) Tout le plaisir est pour moi. Paris: Hachette.

FREUD, S. (1973) Obras completas. Madrid: Biblioteca Nueva.

(1905) “Tres ensayos para uma teoria sexual”, v. II, p.1.169-1.238.

(1915) "Los instintos y sus destinos”, v. II, p. 2.039-2.053.

(1920) "Más allá del principio del placer”, v. III, p. 2.507-2.542.

(1924) “El problema económico del masoquismo", v.III, p. 2.7522.761.

QUINTANA DE GÓMEZ, G. (2000) “Maternidade e Alteridade. Atenas, as Luzes e Freud”. Tese de Doutorado, Instituto de Medicina Social, Universidade do Estado de Rio de Janeiro.

(2003) "Quem cuida de quem cuida?”, in ARÁN, M. (org.).

Soberanias. Rio de Janeiro: Contracapa (Espaço Brasileiro de Estudos Psicanalíticos).

ROSENBERG, B. (2003) Masoquismo mortífero e masoquismo guardião da vida. São Paulo: Escuta.

SCHNEIDER, M. (1980) Freud et le plaisir. Paris: Denoel. (1991) "La proximité chez Levinas et le Nebenmensch freudien”, in Cahier de l'Herne Emmanuel Levinas. Paris: Herne. (1992) La part de l'ombre. Paris: Aubier. . (2000) Genéalogie du masculin. Paris: Aubier.

SISSA, J. (1999) O prazer e o mal. Rio de Janeiro: Civilização Brasileira.

Graciela Quintana de Gómez

gracielaqg@yahoo.com.br 